\title{
Model Latihan Keterampilan Groundstroke Pada Cabang Olahraga Tenis Lapangan
}

\author{
Hazrina Amni, Iman Sulaiman, Hernawan \\ Program Pascasarjana Pendidikan Olahraga, Universitas Negeri Jakarta
}

\begin{tabular}{|c|c|}
\hline \multirow[b]{2}{*}{$\begin{array}{l}\text { Kata Kunci: } \\
\text { Latihan, keterampilan, } \\
\text { Groundstroke, tenis lapangan }\end{array}$} & Abstract \\
\hline & Penelitian ini bertujuan untuk menghasilkan model-model latihan \\
\hline & $\begin{array}{l}\text { groundstroke pada cabang olahraga tenis lapangan dengan menguji } \\
\text { efektifitas terhadap latihan groundstroke pada cabang olahraga tenis } \\
\text { lapangan dengan fokus usia atlet } 14-16 \text { tahun. Metode penelitian yang } \\
\text { digunakan dalam penelitian ini yaitu metode penelitian dan pengembangan } \\
\text { (Research and Development) dari Borg and Gall dengan menggunakan } 10 \\
\text { tahapan. Subjek dalam penelitian ini melibatkan atlet usia } 14-16 \text { tahun. } \\
\text { Rancangan item model divalidasi oleh } 3 \text { ahli pakar tenis lapangan yang } \\
\text { terdiri dari } 1 \text { dosen tenis lapangan UNJ, } 1 \text { dosen biomekanika olahraga UNJ } \\
\text { dan } 1 \text { pelatih tenis cibinong prestasi. Peningkatan latihan keterampilan } \\
\text { groundstroke pada cabang olahraga tenis lapangan pada saat pre-test } \\
\text { menunjukan signifikansi pada t-hitung }=-8,718 \text {, df }=19 \text { dan p-value=0,00< } \\
0,05 \text { artinya terdapat perbedaan yang signifikan pada model latihan } \\
\text { keterampilan groundstroke sebelum dan sesudah diberikan perlakuan } \\
\text { model latihan. Dapat disimpulkan bahwa model latihan keterampilan } \\
\text { groundstroke yang dikembangkan efektif untuk meningkatkan latihan } \\
\text { groundstroke untuk atlet atlet usia } 14-16 \text { tahun }\end{array}$ \\
\hline
\end{tabular}

\begin{abstract}
This study aims to produce models of groundstroke training in the field of tennis tennis by testing the effectiveness of groundstroke training in the field of tennis tennis with a focus on athletes aged 14-16 years. The research method used in this research is the research and development method (Research and Development) from Borg and Gall using 10 stages. The subjects in this study involved athletes aged 14-16 years. The design of the item model was validated by 3 field tennis experts consisting of $1 \mathrm{UNJ}$ field tennis lecturer, 1 UNJ sports biomechanics lecturer and 1 Cibinong achievement tennis trainer. The increase in groundstroke skills training in the field of tennis in pre-test showed significance at t-count $=-8.718, \mathrm{df}=19$ and $\mathrm{p}$-value $=0.00$ $<0.05$ meaning that there was a significant difference in the groundstroke skills training model before and after the treatment model is given treatment. It can be concluded that the developed groundstroke skill training model is effective to improve groundstroke training for athletes aged 14-16 years old.
\end{abstract}

(C) 2019UniversitasPendidikan Indonesia

\footnotetext{
Alamat korespondensi:

Jl. Rawamangun Muka, RT.11/RW.14. Rawamangun, Kecamatan Pulo

Gadung, Kota Jakarta Timur, Daerah Khusus Ibu Kota Jakarta 13220E-mail:

vienavin04@gmail.com
}

eISSN:2549-6360 


\section{PENDAHULUAN}

Indonesia merupakan salah satu negara yang memiliki prestasi olahraga yang baik. Prestasi olahraga tersebut adalah olahraga tenis lapangan. Tercatat dalam pergelaran Asian Games pada bulan Agustus 2018 yang digelar di Indonesia cabang olahraga tenis lapangan memiliki catatan yang baik sebagai tuan rumah karena bisa meraih satu medali emas pada nomor pertandingan mix double. Prestasi yang baik ini bisa dipertahankan dengan adanya regenerasi untuk perekrutan dan pembinaan atlet sehingga potensi yang ada bisa dibina dalam jangka waktu yang panjang dan didukung dengan atlet yang berbakat. Atlet yang berbakat mempunyai peluang yang lebih besar untuk mencapai prestasi yang tinggi. Tidak hanya atlet, sekarang ini olahraga tenis semakin populer dan banyak digemari di kalangan masyarakat, baik itu anakanak, dewasa hingga lansia.

Tenis lapangan merupakan salah satu olahraga yang sudah sangat tua. Pada tahun 1500 sebelum masehi tenis dimainkan di dinding sebuah kuil di mesir dan dimainkan pada saat upacara keagamaan. Tennis can be conceived of as having originally been a relative of medieval football, played with similar rules by the clergy in the cloisters of their monasteries (Gillmeister, 2008). Tenis bisa dimainkan antara sepasang orang (satu lawan satu) atau 4 orang (dua lawan dua) yang memerlukan suatu kecepatan kaki, ketepatan, stamina, antisipasi, dan kecerdikan dalam membaca situasi dalam pertandingan. After experiencing the propagation, development, comprehensive improvement and innovation periods, it has now become a worldwide sport aiming at being "higher, faster, more complete, more accurate and speed-changing. (Wang \& Liu, 2018).

Perkembangan tenis ini cukup pesat, dilihat dari begitu banyak lapangan tenis yang tersedia dan diselenggarakannya turnamen yang diikuti oleh para petenis muda. Sasaran dilakukannya pembinaan atau latihan bagi atlet adalah untuk meningkatkan keterampilan dan prestasi maksimal (Harsono, 2017). Prestasi maksimal bisa dimiliki karena mempunyai fondasi fisik yang baik. "The stronger the physical foundation, the greater the potential for developing technical, tactical, and psychological attributes" (Bompa \& Haff, 2009). Terdapat dua keterampilan di dalam tenis lapangan yaitu keterampilan groundstroke forehand dan groundstroke backhand.

Keterampilan adalah kemampuan untuk membuat hasil akhir dengan kepastian yang maksimum dan pengeluaran energi dan waktu yang minimum (Nasution, 2015). Keterampilan adalah kemampuan untuk melaksanakan tugastugas gerak tertentu dengan baik (Nurhidayah \& Sukoco, 2015). Keterampilan adalah kemampuan untuk menerapkan beberapa teknik secara maksimal dengan sedikit mengeluarkan tenaga atau waktu. Yudiana (Permadi, 2016).

keterampilan teknik seseorang dikembangkan melalui latihan-latihan yang dilakukan secara sistematis, terencana, dan mempertimbangkan prinsip-prinsip latihan. Prinsip latihan dalam setiap cabang olahraga sangatlah penting bagi atlet karena dapat mendukung upaya peningkatan kualitas latihan yang dijalani agar bisa meraih prestasi.

Groundstroke adalah pukulan yang dilakukan setelah bola menyentuh lapangan atau sesudah mantul dari lapangan (Prasetiono \& Gandasari, 2018). Pukulan ini dapat dilakukan dari seluruh sisi lapangan dan biasanya pemain melakukannya dari garis belakang lapangan dan dipukul setelah bola memantul (Siahaan, 2019). Groundstroke dibagi menjadi dua bagian yaitu groundstroke forehand dan groundstroke backhand. Groundstroke forehand merupakan pukulan atau stroke yang paling penting di permainan tenis. The forehand groundstroke is critical to tennis success because it is the most frequently played stroke in tennis and significantly influences match outcome. Within the competitive tennis community, it is common knowledge that points are often won or lost with strong and consistent forehand groundstrokes (Kwon et al., 2017). Sedangkan Groundstroke Backhand adalah pukulan yang sangat menentukan dalam bermain tenis, karena backhand groundstroke juga salah satu pukulan yang sering digunakan dalam permainan tenis dan dalam kenyataannya backhand groundstroke sering kali digunakan untuk mendapatkan poin (Purnomo, 2007).

Pada penelitian ini hanya membuat item model latihan groundstroke forehand drive dan groundstroke backhand drive. Forehand drive adalah salah satu teknik dasar yang harus dikuasai seorang pemain tenis untuk melakukan serangan dan menciptakan suatu point atau angka dalam suatu pertandingan (Arisman, 2016). The forehand drive is one of the most commonly used struck techniques in tennis, both on training and matches (Sawali, 2018). Sedangkan Backhand adalah pukulan yang dilakukan dengan tangan kanan tetapi dari sebelah kiri badan (Sulistyatna, 2015). Backhand drive adalah pukulan groundstroke yang dilakukan oleh pemain tangan kanan dengan lengan menyilang di depan tubuh ke arah kiri 
atau pemain kidal dengan lengan menyilang di depan tubuh ke arah kanan dengan sekuat tenaga dan tajam serta jatuhnya bola berada di daerah belakang lapangan lawan (Siregar, 2017).

Ditinjau dari klub yang ada di Jawa Barat, menurunnya tingkat prestasi yang mengakibatkan peringkat nasional putra/putri menurun pada atlet usia 14-16 yang ada disana dalam penguasaan teknik dasar groundstroke forehand dan groundstroke backhand yang masih kurang penguasaannya, salah satunya dibuktikan dengan data diperoleh oleh PP PELTI.

Menurut Kriese (1988) mengatakan bahwa "rata-rata pemain melakukan Groundstroke dalam permainan 35 - 45\% dari keseluruhan pukulan selama permainan atau pertandingan" (Palmizal, 2011). Maka dari itu perlunya model latihan yang bervariasi agar bisa menarik perhatian atlet untuk terus semangat berlatih agar bisa menguasai keterampilan groundstroke forehand dan groundstroke backhand yang baik sehingga bisa mencapi suatu prestasi yang maksimal.

Komponen keberhasilan dalam pukulan groundstroke berdasarkan pengalaman pelatih tenis Jawa Barat yaitu; mampu memukul bola yang diumpan oleh feeder mengunakan tangan dan mengarahkan bola tersebut ke sisi lapangan yang susah untuk dijangkau lawan. Keberhasilan groundstroke harus memperhatikan balance tubuh yang paling penting. Karena apabila kita tidak seimbang, kita tidak bisa memukul bola dengan sempurna. Tahapan dasar dalam memukul dimulai dari tahapan awalan, pelaksanaan dan akhiran.

Berdasarkan hasil observasi yang telah dilakukan, maka dianggap perlu adanya inovasi dan kreativitas model latihan keterampilan groundstroke. Pentingnya inovasi dan kreativitas serta keterampilan yang baik dalam proses latihan keterampilan groundstroke untuk atlet usia 14-16 tersebut, sehingga pelatih dapat memberikan nuansa yang baru kepada atlet sehingga atlet tidak bosan terhadap materi groundstroke yang telah ada sebelumnya. Maka dari itu, peneliti akan mengembangkan sebuah produk berupa model latihan groundstroke forehand dan groundstroke backhand melalui penelitian: "Model latihan keterampilan groundstroke pada cabang olahraga tenis lapangan".

Berdasarkan penelitian yang ada sebelumnya tentang model rangkaian tes keterampilan tenis lapangan pada pemain putra kelompok usia 12-14 tahun, pada penelitian ini saya melibatkan usia 14-16 tahun serta keterampilan groundstroke forehand drive dan groundstroke backhand drive sebagai keterbaruan pada model latihan keterampilan groundstroke pada cabang olahraga tenis lapangan.

\section{METODE}

Metode penelitian yang digunakan dalam penelitian ini adalah Research and Development (R\&D) dari Borg and Gall. Hasil akhir penelitian ini akan menghasilkan sebuah produk yang dapat digunakan sebagai model latihan keterampilan groundstroke pada cabang olahraga tenis lapangan dengan variasi model yang baru. Penelitian R\&D dalam Borg and Gall memiliki 10 langkah penelitian.

Pertama Research and Information Collecting (Analisis Kebutuhan) ini didapat dari hasil pengamatan, observasi, dan wawancara yang dilakukan kepada atlet dan pelatih serta dari kejadian yang ada dilapangan. Sehingga, dapat disimpulkan bahwa analisis kebutuhan pada masalah yang ada, dan ide dalam pengembangan ini adalah perlu adanya model latihan yang baru untuk memperbaiki hasil keterampilan groundstroke para atlet.

Kedua, Planning (Perencanaan Pengembangan Model) yaitu membuat produk awal berupa rangkaian pengembangan model latihan keterampilan groundstroke pada cabang olahraga tenis lapangan. Model ini nantinya akan dijadikan sebagai pedoman atau petunjuk untuk meningkatkan kualitas sehingga bisa memperoleh hasil latihan yang baik.

Ketiga, Development of The Preliminary From Of Product (Desain Produk)

\section{Tabel 1 Desain Produk Model Latihan Keterampilan Groundstroke}

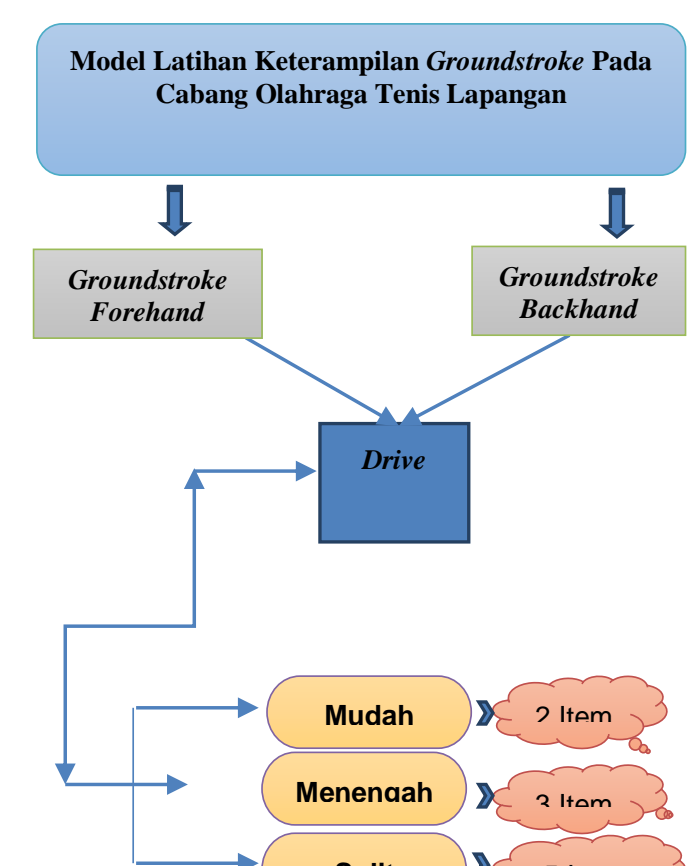


Keempat, Preliminary Field Testing (Uji Coba Lapangan Tahap Awal) melibatkan subjek yaitu para ahli dibidang yang akan diteliti yaitu 3 ahli dibidang olahraga tenis lapangan baik dibidang akademis maupun praktisi. Hasil dari uji coba lapangan tahap awal akan dijadikan masukan dalam menyempurnakan rancangan model latihan keterampilan groundstroke pada cabang olahraga tenis lapangan sebelum dilakukan uji coba kepada kelompok kecil.

Kelima, Main Product Revision (Revisi Produk Tahap Awal) merevisi hasil dari uji coba kelompok kecil yang telah dillakukan sebelumnya sebagai bahan untuk memperbaiki model latihan sebelum di uji ke lapangan utama.

Keenam, Main Field Testing (Uji Lapangan Utama) uji coba lapangan yang dilakukan setelah model latihan dilakukan revisi dari hasil uji coba sebelumnya. Uji coba dilakukan pada klub yang ada di Jawa Barat sebanyak 30 atlet usia 14-16.

Ketujuh, Operational Product Revision (Revisi Produk) Setelah pelaksanaan uji kelompok besar maka selanjutnya melakukan revisi berdasarkan masukan-masukan evaluasi perbaikan model. Evaluasi pada tahapan ini merupakan evaluasi akhir model dari model latihan keterampilan groundstroke terhadap atlet klub Jawa Barat.

Kedelapan, Operational Field Testing (Uji Efektivitas) bertujuan untuk (1) untuk mengetahui apakah desain model telah diterapkan dengan baik dan benar, dan (2) seberapa efektifkah hasil penerapan model terhadap tujuan penelitian ini. Maka dari itu pendekatan kuantitatif digunakan untuk mencari efektifitas tersebut dengan rancangan penelitian pra eksperimen berbentuk one group pretest-posttest design design". Langkahlangkah yang dilakukan adalah sebagai berikut : 1) menetapkan kelompok subjek penelitian sebagai kelompok eksperimen dan kelompok control, 2) melaksanakan pre-test, 3) mencoba model latihan keterampilan groundstroke, 4) melaksanakan posttest, 5) mencari rata-rata skor hasil pre-test dan post-test untuk membandingkan keduanya, 6) mencari selisih perbedaan kedua rata-rata tersebut melalui metode statistic (uji-t) untuk mengetahui apakah terdapat pengaruh yang signifikan dari penggunaan model latihan tersebut.

\section{Tabel 2. Desain Penelitian Uji Efektifitas Model}

Langkah yang dilakukan dalam uji coba ini antara lain; (1) menetapkan kelompok subjek penelitian; (2) melaksanakan pretest $\left(\mathbf{O}_{\mathbf{1}}\right)$; (3) mencoba model yang telah dikembangkan; (4) melaksanakan post-test $\left(\mathrm{O}_{2}\right)$; (5) mencari skor rata-rata pretest dan posttest dan dibandingkan antar keduanya; (6) mencari selisih perbedaan kedua rata-rata tersebut melalui metode statistic (uji-t) untuk mengetahui ada tidaknya pengaruh yang signifikan dari penggunaan model.

Kesembilan, Final Product Revision (Perbaikan dan Penyempurnaan Produk Akhir) terhadap item model latihan yang dikembangkan sehingga menghasilkan produk akhir yang tepat sesuai dengan keinginan.

Kesepuluh, Dissemination and Implementaion (Mendesiminasi dan mengimplementasikan produk) serta menyebarluaskan produk dari model yang dikembangkan agar bisa digunakan oleh semua orang.

\section{HASIL DAN PEMBAHASAN}

Dari hasil penelitian didapatkan atlet tenis lapangan usia 14-16 tahun untuk uji coba kelompok kecil sebanyak 15 atlet, uji coba kelompok besar atau uji coba lapangan utama sebanyak 30 atlet dan uji efektifitas sebanyak 20 atlet tenis lapangan usia 14-16 tahun. Efektifitas model menggunakan rencangan penelitian praeksperimen berbentuk "Two group pretestposttest design". Langkah-langkah yang dilakukan adalah sebagai berikut : 1) menetapkan kelompok subjek penelitian sebagai kelompok eksperimen dan kelompok control, 2) melaksanakan pre-test, 3) mencoba model latihan keterampilan groundstroke, 4) melaksanakan posttest, 5) mencari rata-rata skor hasil pre-test dan post-test untuk membandingkan keduanya, 6) mencari selisih perbedaan kedua rata-rata tersebut melalui metode statistic (uji-t) untuk mengetahui apakah terdapat pengaruh yang signifikan dari penggunaan model latihan tersebut. 


\begin{tabular}{cccc}
\hline Subjek & Pretest & Perlakuan & Posttest \\
\hline R & O1 $_{1}$ & X & O $_{2}$ \\
\hline
\end{tabular}

Tabel 4 One Sample Kolmogorov Smirnov

\begin{tabular}{llcc}
\hline & & Pretest & Posttest \\
\hline $\mathrm{N}$ & & 20 & 20 \\
Normal & Mean & 38.70 & 39.50 \\
Parameters $^{\mathrm{a}}$ & Std. Deviation & 2.618 & 2.417 \\
Most Extreme & Absolute & .154 & .168 \\
Differences & Positive & .154 & .168 \\
& Negative & -.096 & -.126 \\
Kolmogorov-Smirnov Z & .690 & .752 \\
Asymp. Sig. (2-tailed) & .727 & .625 \\
\hline
\end{tabular}

a.Test distribution is Normal.

Berdasarkan tabel di atas yang dihitung menggunakan SPSS hasil darik kolmogorovSmirnov Test diperoleh data normalitas pada pre-test 0.690 dan pada kelompok pos-test 0.752 yang mana kedua data tersebut lebih besar dari alpha 0.05. Dengan demikian dapat disimpulkan bahwa kedua data berasal dari populasi yang berdistribusi normal.

Tabel 5

Paired Samples Statistics (Pre-test) dan (Post-test) kelompok eksperimen

Paired Samples Statistics

\begin{tabular}{cccccc} 
& & Mean & $\mathrm{N}$ & Std. Deviation & $\begin{array}{c}\text { Std. Error } \\
\text { Mean }\end{array}$ \\
\hline Pair & PRE_TEST & 38.70 & 20 & 2.618 & .585 \\
1 & & 39.50 & 20 & 2.417 & .540 \\
\hline
\end{tabular}

Nilai rata-rata atlet sebelum diberikan model latihan adalah 38,70 dan nilai setelah diberikan perlakuan 18 item model latihan keterampilan groundstroke adalah 39,50 yang artinya bahwa terdapat peningkatan yang dihasilkan dari pretest dan post-test sehingga terlihat keterampilan groundstroke pada cabang olahraga tenis lapangan

Tabel 6

Hasil Paired Correlation (Pre-test) dan (Post-test) Kelompok Eksperimen Paired Samples Correlations

\begin{tabular}{ccccc}
\hline & & N & Correlation & Sig. \\
\hline Pair 1 & $\begin{array}{c}\text { PRE_TEST \& } \\
\text { POS_TEST }\end{array}$ & 20 & .990 & .000 \\
\hline
\end{tabular}


Berdasarkan tabel diatas didapat bahwa koefisien korelasi model latihan keterampilan groundstroke pada cabang olahrga tenis lapangan sebelum dan sesudah diberikan perlakuan model latihan keterampilan groundstroke adalah 0.990 p-value 0,00 $<0,05$ jadi kesimpulannya adalah terdapat hubungan secara signifikan. Pada uji perbedaan rerata dengan SPSS diperoleh mean $=-0.800$ menunjukkan selisih dari pre-test dan hasil posttest, hasil t-hitung $=-8.718, \mathrm{df}=19 \mathrm{dan} \mathrm{p}$-value $=0.00<0.05$ yang berarti terdapat perbedaan yang signifikan antara sebelum dan sesudah diberikan perlakuan model latihan keterampilan groundstroke.

Tabel 7. Paired Samples Statistic (Pre-test) dan (Post-test) Kelompok Eksperimen

\begin{tabular}{|c|c|c|c|c|c|c|c|c|c|}
\hline & & \multicolumn{5}{|c|}{ Paired Differences } & $\mathrm{t}$ & $\mathrm{df}$ & Sig. (2-tailed) \\
\hline & & \multirow[t]{2}{*}{ Mean } & \multirow[t]{2}{*}{ Std. Deviation } & \multirow[t]{2}{*}{$\begin{array}{l}\text { Std. Error } \\
\text { Mean }\end{array}$} & \multicolumn{2}{|c|}{$\begin{array}{l}95 \% \text { Confidence } \\
\text { Interval of the } \\
\text { Difference }\end{array}$} & & & \\
\hline & & & & & Lower & Upper & & & \\
\hline Pair 1 & $\begin{array}{c}\text { PRE_TEST - } \\
\text { POS_TEST }\end{array}$ & -.800 & .410 & .092 & -.992 & -.608 & -8.718 & 19 & .000 \\
\hline
\end{tabular}

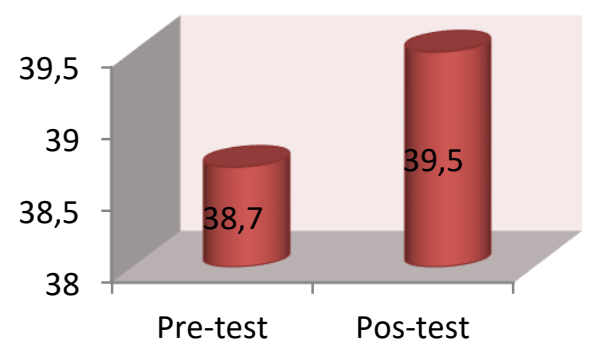

Gambar 3. Diagram Uji Efektifitas Produk Kelompok Eksperimen

Tabel 9. Paired Sample Statistic Pre-test dan Post-test Kelompok Kontrol

\begin{tabular}{llcccc}
\hline & & Mean & N & $\begin{array}{c}\text { Std. } \\
\text { Deviation }\end{array}$ & $\begin{array}{c}\text { Std. Error } \\
\text { Mean }\end{array}$ \\
\hline Pair 1 & PRE_TEST & 37.65 & 20 & 2.033 & .455 \\
& POS_TEST & 38.55 & 20 & 2.064 & .462 \\
\hline
\end{tabular}

Tabel 10. Paired Sample Correlation (Pre-test) dan (Post-test) kelompok control

\begin{tabular}{ccccc}
\hline & & N & Correlation & Sig. \\
\hline Pair 1 & $\begin{array}{c}\text { PRE_TEST \& } \\
\text { POS_TEST }\end{array}$ & 20 & .976 & .000 \\
\hline
\end{tabular}

Tabel 11. Paired Sample Statistics (Pre-test) dan (Post-test) kelompok control 


\begin{tabular}{|c|c|c|c|c|c|c|c|c|c|}
\hline & & \multicolumn{5}{|c|}{ Paired Differences } & $\mathrm{t}$ & $\mathrm{df}$ & $\begin{array}{l}\text { Sig. (2- } \\
\text { tailed) }\end{array}$ \\
\hline & & \multirow[b]{2}{*}{ Mean } & \multicolumn{4}{|c|}{$\begin{array}{cc}\text { 95\% Confidence } \\
\text { Interval of the } \\
\text { td. Error } \quad \text { Difference }\end{array}$} & & & \\
\hline & & & Deviation & Mean & Lower & Upper & & & \\
\hline Pair 1 & PRE_TEST - POS_TEST & -.900 & .447 & .100 & -1.109 & -.691 & -9.000 & 19 & .000 \\
\hline
\end{tabular}

Berdasarkan tabel di atas dan hasil SPSS menunjukan hasil pre-test dan pos-test atlet usia 14-16 tahun saat melakukan gerakan groundstroke forehand drive dan groundstroke backhand drive di games yang sesungguhny. Nilai rata-rata tes 20 atlet usia 14-16 tahun pada saat pre-test adalah 37,65 dan rata-rata pos-test adalah 38,55. Sedangkan hasil koefisien korelasi adalah $0.00<0.05$, maka terdapat hubungan yang signifikan. Pada uji beda didapatkan mean $=$ $-0,900$. t-hitung $=-9.000 . \mathrm{df}=19$ dan $p$-value $=$ $0.00<0.05$ yang berarti terdapat perbedaan.

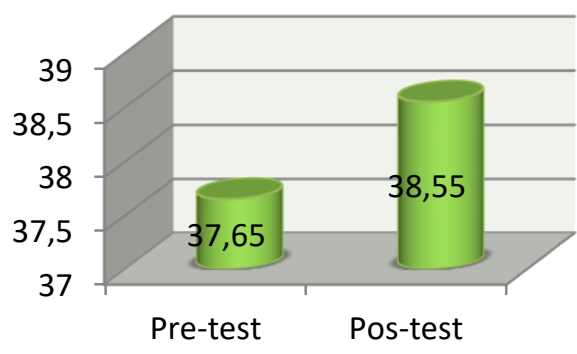

Gambar 4. Diagram Uji Efektifitas Produk Kelompok Eksperimen

Berdasarkan perolehan data diatas dapat disimpulkan bahwa model latihan keterampilan groundstroke ini layak untuk digunakan serta efektif untuk meningkatkan suatu keterampilan groundstroke sehingga bisa melakukan penempatan pukulan yang baik. Hasil test yang didapatkan sebelum dan sesudah diberikan perlakuan model latihan keterampilan groundstroke pada cabang olahraga tenis lapangan dalm uji signifikannya yang dilakukan menggunakan SPSS 16 didapat nilai mean = 0.800 yang menunjukkan selisih dari hasil pretest dan post-test, hasil t-hitung $=-8.718, \mathrm{df}=19$ dan $\mathrm{p}$-value $=0.00<0.05$ yang menunjukan bahwa terdapat perbedaan yang signifikan antara sebelum dan sesudah diberikan perlakuan model latihan groundstroke pada cabang olahraga tenis lapangan. Berdasarkan hasil yang didapatkan dari penelitian maka disimpulkan

\section{KESIMPULAN}

Berdasarkan hasil penelitian dan pembahasan yang telah diuraikan diatas, maka hasil penelitian ini dapat disimpilkan bahwa:

Dapat Menghasilkan produk akhir berupa model latihan keterampilan groundstroke pada cabang olahraga tenis lapangan yang terdiri dari 18 item model latihan keterampilan groundstroke forehand drive dan groundstroke backhand drive serta model latihan keterampilan groundstroke ini diharapkan bisa lebih meningkatkan kemampuan atlet usia 14-16 tahun serta mencegah kejenuhan atlet dalam berlatih, dikarenakan model latihan yang bervariasi sehingga proses latihan berjalan dengan lancar tanpa membosankan atlet.

\section{DAFTAR PUSTAKA}

Arisman. (2016). Kontribusi Koordinasi MataTangan Dan Fleksibilitas Terhadap Ketepatan Pukulan Forehand Drive Pada Klub Ptl (Pelatihan Tenis Lapangan) 
Padang. IImu Kependidikan, 14(September), 68-82.

Bompa, T. O., \& Haff, G. (2009). Periodization: Theory and methodology of training. Human Kinetics.

Gillmeister, H. (2008). Tennis History, 15(46), 16-18.

Harsono. (2017). Kepelatihan olahraga teori dan metodologi. Bandung: PT. Remaja Rosdakarya.

Kwon, S., Pfister, R., Hager, R. L., Hunter, I., \& Seeley, M. K. (2017). Influence Of Tennis Racquet Kinematics On Ball Topspin Angular Velocity And Accuracy During The Forehand Groundstroke, (October), 505-513.

Nasution, N. S. (2015). Hubungan Kekuatan Otot Lengan Dan Percaya Diri Dengan Keterampilan Open Spike Pada Pembelajaran Permainan Bola Voli Atlet Pelatkab Bola Voli Putri Kabupaten Karawang. Pendidikan Unsika,
3(November), 188-199.

Nugroho, U. (2015a). Analisis Biomekanika Forehand Groundstruke Atlet Yunior Daerah Istimewa Yogyakarta. Ilmiah Penjas, 1(1), 49-62.

Nurhidayah, \& Sukoco, P. (2015). Pengaruh Model Latihan Dan Koordinasi Terhadap Keterampilan Siswi Ekstrakurikuler Bola Basket Smpn I Bantul. Jurnal Keolahragaan, 3(April), 66-78.

Permadi, A. A. (2016). Pengaruh Model Latihan Fisik Dan Kecerdasan Emosi Terhadap Keterampilan Sepakbola. Jurnal IImu Pendidikan Dan Pengajaran, 3(2), 135148.

Prasetiono, B. A., \& Gandasari, M. F. (2018). Model Rangkaian Tes Keterampilan Tenis Lapangan Pada Pemain Putra Kelompok Usia 12-14, 4.

Purnomo, A. (2007). Hubungan Fleksibilitas Dan Kelincahan 